\title{
A PRESUNÇÃO DE VIOLÊNCIA NOS DELITOS SEXUAIS COM VÍTIMAS MENORES DE IDADE
}

\author{
JACOB SAUER \\ Universidade de Buenos Aires \\ Pesquisa DOUTORAL
}

\section{Resumo}

O presente trabalho objetiva analisar a presunção de violência no caso de relações sexuais com menores de idade, com consentimento destes. No Brasil, é antiga a discussão sobre se dita presunção seria relativa e admite-se, assim, prova em sentido contrário, ou absoluta, o que não permite discussão a respeito da validade do consentimento do menor de idade.

Destarte, após breve análise da tutela penal da liberdade sexual e do atual panorama legislativo brasileiro, serão analisadas as razões de cada uma das orientações vigentes, procurando-se destacar, ao final, a importância da discussão para as políticas de repressão à exploração sexual infantil.

Palavras-chave: abuso sexual, prostituição, Direito Penal, Direitos da Criança.

El autor: Estudante de doutorado em Direito. Viamonte 430/44, 1053, Buenos Aires, Argentina.

Recebido: 23 de julho de 2014; avaliado: 18 de agosto de 2014: aceito: 29 de outubro de 2014 


\title{
THE ASSUMPTION OF VIOLENCE IN SEX CRIMES WITH MINOR VICTIMS
}

\author{
JACOB SAUER \\ Universidade de Buenos Aires \\ Pesquisa doutoral
}

\begin{abstract}
This work aims to analyze the presumption of violence in the case of sexual intercourse under consent with minors. In Brazil, there is the old argument about whether the presumption would be relative and admited, even with evidence of the contrary, or absolute, not allowing discussion of the validity of the consent of the minor.

Thus, after a brief analysis of the penal protection of sexual freedom and the current Brazilian regulatory landscape, the paper analyzes the reasons for each of the current guidelines, seeking to highlight, in the end, the importance of this discussion for the repression policies against children's sexual exploration.
\end{abstract}

Keywords: Sexual abuse, prostitution, criminal law, children's rights.

About the autor: PhD. candidate in the field of law. Viamonte 430/44, 1053, Buenos Aires, Argentina.

Received: July 23, 2014; reviewed: August 18, 2014; accepted: october 29, 2014 


\section{Introdução}

O presente trabalho objetiva analisar a presunção de violência no caso de relações sexuais com menores de idade, com consentimento destes. No Brasil, é antiga a discussão sobre se dita presunção seria relativa e, admite-se, assim, prova em sentido contrário, ou absoluta, o que não permite discussão a respeito da validade do consentimento do menor de idade.

A discussão ganhou contornos de atualidade com a edição da Lei 12.015 de 2009, a qual introduziu no Código Penal Brasileiro o art. 217-A, especificamente destinado a tutelar a liberdade sexual do vulnerável. Claramente, o intuito do legislador foi aplacar as discussões e tornar expresso o caráter absoluto da presunção de violência; contudo, como se verá, decorridos alguns anos de vigência das alterações legislativas, já se percebem correntes doutrinárias e jurisprudenciais no sentido da relativização daquela presunção.

Destarte, após breve análise da tutela penal da liberdade sexual e do atual panorama legislativo brasileiro, serão analisadas as razões de cada uma das orientações vigentes, procurando-se destacar, ao final, a importância da discussão para as políticas de repressão à exploração sexual infantil.

\section{Fundamentação}

\section{Antecedentes históricos da legislação protetiva dos menores}

Desde o momento em que o Estado passou a intervir nas relações privadas para tutela da dignidade humana no viés da liberdade sexual, o legislador demonstrou especial atenção às crianças e adolescentes. Estes, ainda sem formação intelectual completa, não dispõem de discernimento e maturidade para entender as implicações e consequências de suas escolhas nas questões relativas à sexualidade, o que permite que se tenha por inválido eventual consentimento com práticas sexuais.

Nesse passo, desde a época imperial têm-se criado em terras brasileiras leis que limitam as possibilidades de consentimento válido de menores com práticas sexuais, limites esses que, com a evolução dos costumes de cada geração, vêm sofrendo mudanças significativas. Assim, no Código Penal de 1832, a presunção de violência em relação a atos sexuais que envolvessem menores estava expressa no art. 219, 
acrescido do Aviso 512 de 1862, no qual se estabelecia a idade de consentimento válido em 17 anos e considerava que a mulher até essa idade não tinha entendimento para tal prática. ${ }^{1}$ Com o advento do Código Penal de 1890, reduz-se a idade de presunção de violência para 16 anos.

Em 1940, entra em vigor o atual Código Penal, por meio do Decreto-lei 2.848 de 1940, no qual se reduz novamente a idade-limite da presunção de violência para 14 anos, sob a justificativa de adequação aos avanços sociais e culturais. Era a seguinte a redação original do art. 224 daquele diploma:

Art. 224. Presume-se a violência, se a vítima:

a) não é maior de 14 (catorze) anos;

b) é alienada ou débil mental, e o agente conhecia esta circunstância;

c) não pode, por qualquer outra causa, oferecer resistência.

Em que pese a textualidade da norma, acabou prevalecendo na jurisprudência orientação segundo a qual a presunção de violência no caso de menores de 14 anos seria relativa, ou seja, poderia ser afastada quando as circunstâncias do caso concreto demonstrassem que a vítima já possuísse iniciação e alguma desenvoltura sexual, a ponto de se ter por válido o seu consentimento. É o que se depreende do seguinte acórdão do Superior Tribunal de Justiça, órgão encarregado da uniformização da interpretação da legislação infraconstitucional:

AGRAVO REGIMENTAL. RECURSO ESPECIAL. PENAL. ART. 224 DO CP. ESTUPRO COM VIOLÊNCIA PRESUMIDA. INEXISTÊNCIA DE VIOLÊNCIA. CONSENTIMENTO DA VÍTIMA. ACÓRDÃO A QUO EM CONSONÂNCIA COM A JURISPRUDÊNCIA DA SEXTA TURMA DO STJ. SÚMULA 83/STJ.

1. O cerne da controvérsia cinge-se a saber se a presunção de violência do art. 224 do Código Penal se revela de natureza relativa (iuris tantum). 2. A corrente majoritária, doutrinária e jurisprudencial, pende em favor da natureza relativa da presunção da violência acentuada no art. 224 do Código Penal, ao afirmar que a existência de determinados fatores impõe, em situações tais, o afastamento da presunção. 3. No caso, o acórdão recorrido firmou-se em consonância com a jurisprudência da Sexta Turma deste Tribunal, no sentido de considerar relativa a presunção de violência pela menoridade, anteriormente prevista no art. 224, a, do Código Penal —revogado pela Lei no 12.015/2009—,

www.fontedosaber.com/direito/violência-sexual-presumida-para-maiores-de-14 (Acesso em 9 nov. 2013). 
conforme a situação do caso concreto, quando se tratar de vítima menor de 14 e maior de 12 anos de idade. 4. Incidência da Súmula 83/STJ. 5. O agravo regimental não merece prosperar, porquanto as razões reunidas na insurgência são incapazes de infirmar o entendimento assentado na decisão agravada. 6. Agravo regimental improvido. (AgRg no Recurso Especial no 1214407/SC (2010/0169901-0), 6a Turma do STJ, Rel. Sebastião Reis Júnior. j. 13.09.2011, unânime, DJe 28.09.2011).

No ano de 2009, diante da necessidade de readequação da legislação atinente aos delitos sexuais, a Lei 12.015 promoveu diversas alterações no Código Penal. ${ }^{2}$ Destaca-se a criação de tipo específico para a tutela de menores de 14 anos, identificado como "estupro de vulnerável":

Art. 217-A. Ter conjunção carnal ou praticar outro ato libidinoso com menor de 14 (catorze) anos:

Pena — reclusão, de 8 (oito) a 15 (quinze) anos.

$\S 1^{\circ}$ Incorre na mesma pena quem pratica as ações descritas no caput com alguém que, por enfermidade ou deficiência mental, não tem o necessário discernimento para a prática do ato, ou que, por qualquer outra causa, não pode oferecer resistência.

$\S 2^{\circ}$ (VETADO)

$\S 3^{\circ}$ Se da conduta resulta lesão corporal de natureza grave:

Pena - reclusão, de 10 (dez) a 20 (vinte) anos.

$\S 4^{\circ}$ Se da conduta resulta morte:

Pena - reclusão, de 12 (doze) a 30 (trinta) anos.

\footnotetext{
Rogério Greco esclarece que a necessidade de readequação atendeu, dentre outros fatores, à demanda de respostas à crescente exploração sexual de crianças e adolescentes: As modificações ocorridas na sociedade pós-moderna trouxeram novas e graves preocupações. Ao invés de procurar proteger a virgindade das mulheres, como acontecia com o revogado crime de sedução, agora, o Estado estava diante de outros desafios, a exemplo da exploração sexual de crianças e adolescentes. A situação era tão grave que foi criada, no Congresso Nacional, uma Comissão Parlamentar Mista de Inquérito, por meio do Requerimento 02/2003, apresentado no mês de março daquele ano, assinado pela Deputada Maria do Rosário e pelas Senadoras Patrícia Saboya Gomes e Serys Marly Slhessarenko, que tinha por finalidade investigar as situações de violência e redes de exploração sexual de crianças e adolescentes no Brasil. Essa CPMI encerrou oficialmente seus trabalhos em agosto de 2004 e trouxe relatos assustadores sobre a exploração sexual em nosso país, culminando por produzir o projeto de Lei 253 de 2004 que, após algumas alterações, veio a se converter na Lei 12.015, de 7 de agosto de 2009 (Rogério Greco, Curso de Direito Penal: parte geral. v. I. 10a ed. (Rio de Janeiro: Impetus, 2008)).
} 
Novamente, percebe-se que o intuito do legislador fora estabelecer presunção absoluta de violência em caso de estupro ${ }^{3}$ em face de menores de 14 anos, pois estabeleceu como crime a prática de conjunção carnal ou outro ato libidinoso em face daqueles, sem qualquer menção à existência de violência. É dizer, pela norma brasileira atualmente vigente, a relação sexual com menor de 14 anos, mesmo que com seu consentimento, caracteriza estupro, punido com pena de reclusão, de 8 (oito) a 15 (quinze) anos.

Alguns doutrinadores sustentam, com razão, que andou mal o legislador em estabelecer a idade mínima para fins de consentimento válido com relações sexuais em 14 anos, pois deveria ter estabelecido o limite em 12 anos incompletos, observando-se assim a condição de "criança" segundo o Estatuto da Criança e do Adolescente. Nesse sentido, leciona Nucci:"

Partimos do seguinte ponto básico: o legislador na área penal continua retrógrado e incapaz de acompanhar as mudanças de comportamento reais na sociedade brasileira, inclusive no campo de definição de criança e adolescente. Perdemos uma oportunidade ímpar de equiparar os conceitos com o Estatuto da Criança e do Adolescente, ou seja, criança é a pessoa menor de 12 anos; adolescente, quem é maior de 12 anos. Logo, a idade de 14 anos deveria ser eliminada desse cenário.

Não obstante, para as finalidades deste trabalho, não é relevante a idade exata em que se estabelece a presunção de violência, o que pode variar conforme a realidade de cada país. Importa, isso sim, considerar se é válida a predefinição de vulnerabilidade segundo o critério cronológico, bem como se, estabelecido legalmente um limite, admitiria exceções conforme as circunstâncias do caso concreto.

\footnotetext{
A partir da Lei 12.015 de 2009, alterou-se também a definição do crime de estupro, antes compreendido como a prática de conjunção carnal mediante violência. Agora, o delito abrange qualquer prática sexual, como se verifica da atual redação do art. 213 do Código Penal:

Art. 213. Constranger alguém, mediante violência ou grave ameaça, a ter conjunção carnal ou a praticar ou permitir que com ele se pratique outro ato libidinoso:

Pena - reclusão, de 6 (seis) a 10 (dez) anos.

$\S 1^{\circ}$ Se da conduta resulta lesão corporal de natureza grave ou se a vítima é menor de 18 (dezoito) ou maior de 14 (catorze) anos:

Pena - reclusão, de 8 (oito) a 12 (doze) anos.

$\S 2^{\circ}$ Se da conduta resulta morte:

Pena- reclusão, de 12 (doze) a 30 (trinta) anos.

4 Guilherme de Souza Nucci, Manual de direito penal. 7a ed. (São Paulo: Revista dos Tribunais, 2011), 245.
} 


\section{A validade do consentimento de menores nas relações sexuais}

A validade do consentimento de menores de idade e doentes mentais com práticas sexuais é objeto de estudo desde a Idade Média. Nesse sentido, esclarece Luiz Regis Prado 5 que duas passagens do "Digesto" motivaram a inserção da presunção de violência, naquelas hipóteses, em várias legislações penais. A primeira, uma passagem de Pompônio, que afirmava: "que os dementes e interditos têm vontade nula"; a segunda, uma passagem de Celso: "o pupilo nem quer, nem deixa de querer". Tais expressões justificam o postulado "que quem não quer nem pode querer, dissente". A partir dessas hipóteses, chegou-se à conclusão de que os atos libidinosos praticados com menores são presumivelmente violentos.

Tradicionalmente, como exposto linhas acima, a legislação brasileira vem acolhendo o critério etário com definidor da vulnerabilidade do menor, sem se vincular, todavia, aos parâmetros definidores da maioridade civil ou penal. Inicialmente estabelecida em 17 anos, com a promulgação do Código Penal de 1940, adotou-se o limite vigente de 14 anos, em atenção à evolução dos costumes sociais. Estes já justificariam nos tempos atuais — também se expôs—a redução do limite para 12 anos, o qual marca a passagem da infância para a adolescência.

Em que pese a falibilidade própria do critério etário, pois iguala seres humanos em fase da vida na qual as diferenças de discernimento podem ser brutais, há que se ter por válida a opção legislativa. Notadamente, porque se está diante de um tipo penal, logo, há necessidade de elementos objetivos para nortear as ações humanas. Basta imaginar-se a insegurança jurídica que adviria de um sistema subjetivo no qual o indivíduo, ao envolver-se sexualmente com um indivíduo menor de idade, estaria sujeito à posterior condenação criminal por entender-se que aquele último não possuía capacidade para consentir. O critério etário tem o mérito, portanto, de afastar discussões em caso de indivíduos com idade superior ao limite legal.

Destarte, orienta-se o legislador por uma presunção de ausência de discernimento suficiente abaixo de uma idade mínima, o que veda a prática de relações sexuais com tais pessoas, em nome da proteção de seus interesses, como leciona Nucci: ${ }^{6}$

Luiz Regis Prado, Curso de direito penal brasileiro. v 2: parte especial, arts. 121 a 249. 9a ed. rev. atual. e ampl. (São Paulo: Editora Revistas dos Tribunais, 2010), 622.

$6 \quad$ Nucci, Manual de direito penal, 243. 
A relação sexual com vulnerável pode não envolver violência ou grave ameaça real, leia-se, pode ter sido "consentida" pelo ofendido, que, após não reclama e pode até ter apreciado. Entretanto, por regras de experiência, captadas pelo legislador, é vedada a prática sexual com tais pessoas, visto que a maioria não tem discernimento suficiente, nem condições de autorizar o ato, logo, a vulnerabilidade de suas situações indica a presunção de ter sido violenta a prática do sexo.

Acolhido o critério etário, contudo, há que se perquirir da possibilidade de excepcioná-lo segundo as condições do caso concreto. É dizer: seria possível entender-se como válido o consentimento de menor de 14 anos com a prática sexual segundo as suas particulares condições de desenvolvimento?

Aparentemente, como já exposto, a literalidade do art. 217-A do Código Penal não permitiria tais digressões, pois se limita a criminalizar a conduta de manter conjunção carnal ou outro ato libidinoso com menor de 14 anos. Dispensa-se completamente o elemento típico da violência, diante do que sequer seria possível se cogitar da presunção de tal elemento. Ora, se o tipo penal dispensa a existência de violência, por qual razão haveria de se presumi-la?

Com base nessa literalidade, a orientação atualmente vigente no Brasil é pela impossibilidade de relativização do tipo penal, entendendo-se como estupro toda e qualquer relação sexual com menor de 14 anos. Para além da interpretação literal, argumenta-se que o tipo penal em questão estabelece um dever geral de abstenção da conduta de manter conjunção carnal ou qualquer ato libidinoso com pessoa menor de 14 anos, segundo a ideia de que tais indivíduos não detêm a capacidade necessária para aquiescer com a prática de atos sexuais.

Daí que seriam indiferentes à consumação do delito o consentimento da vítima, sua compleição física, postura na sociedade ou anterior experiência sexual, pois a vulnerabilidade seria decorrente do mero fato de contar com menos de 14 anos.

Corrente minoritária, porém, ainda sustenta a possibilidade de relativização do conceito de vulnerabilidade dos menores de 14 anos, mediante argumento de que cada caso deve ser analisado em todas as suas particularidades e devem-se considerar fatores como os aspectos físicos da vítima, sua experiência sexual ou as circunstâncias específicas que levaram ao ato sexual. A relativização, sustentam seus adeptos, permitiria julgamento mais justo, em casos tais como o de prostituição das vítimas. 
Nessa linha, há julgado recente do Superior Tribunal de Justiça que bem ilustra as distintas correntes existentes. Eis o teor da ementa do acórdão:

\begin{abstract}
PENAL E PROCESSO PENAL. EMBARGOS DE DIVERGÊNCIA EM RECURSO ESPECIAL. ESTUPRO COM VIOLÊNCIA PRESUMIDA. MENOR DE 14 ANOS. REVOGADO ART. 224, "A", DO CP. PRESUNÇÃO RELATIVA. DIVERGÊNCIA CARACTERIZADA. EMBARGOS DE DIVERGÊNCIA ACOLHIDOS. 1. A violência presumida prevista no revogado artigo 224, "a", do Código Penal, deve ser relativizada conforme a situação do caso concreto, cedendo espaço, portanto, a situações da vida das pessoas que demonstram a inexistência de violação ao bem jurídico tutelado. 2. Embargos de divergência acolhidos. (EREsp 1021634/SP, Rel. Ministra MARIA THEREZA DE ASSIS MOURA, TERCEIRA SEÇÃO, julgado em 23/11/2011, DJe 23/03/2012).
\end{abstract}

No caso em questão, a Terceira Seção do Superior Tribunal de Justiça (STJ), por maioria, considerou que não se pode considerar crime o ato que não viola o bem jurídico tutelado — no caso, a liberdade sexual-. Isso porque as menores a que se referia o processo julgado se prostituíam antes do suposto crime, razão pela qual tanto o magistrado quanto o tribunal local absolveram o réu da acusação, em razão da experiência sexual das vítimas. O Tribunal de Justiça de São Paulo considerou que a própria mãe de uma das supostas vítimas afirmara em juízo que a filha "enforcava" aulas e ficava na praça com as demais para fazer programas com homens em troca de dinheiro. Consta do julgamento pelo TJ/SP: "A prova trazida aos autos demonstra, fartamente, que as vítimas, à época dos fatos, lamentavelmente, já estavam longe de serem inocentes, ingênuas, inconscientes e desinformadas a respeito do sexo. Embora imoral e reprovável a conduta praticada pelo réu, não restaram configurados os tipos penais pelos quais foi denunciado".

Com recurso especial ao Superior Tribunal de Justiça, a Quinta Turma reverteu o entendimento local e decidiu pelo caráter absoluto da presunção de violência no estupro praticado contra menor de 14 anos. A decisão levou a defesa a apresentar embargos de divergência à Terceira Seção, que alterou a jurisprudência anterior do Tribunal para reconhecer a relatividade da presunção de violência na hipótese dos autos. Os embargos de divergência tiveram lugar porque a Sexta Turma do Superior Tribunal de Justiça entendia como relativa a presunção de violência, o que ensejou o recurso para uniformização do entendimento no âmbito interno daquela Corte, quando então acabou prevalecendo entendimento pela relativização da presunção de violência. 
Alguns trechos do voto condutor do julgamento revelam os argumentos considerados ${ }^{\top}$ :

Não me parece juridicamente defensável continuar preconizando a ideia da presunção absoluta em fatos como os tais se a própria natureza das coisas afasta o injusto da conduta do acusado. O direito não é estático, devendo, portanto, se amoldar às mudanças sociais, ponderando-as, inclusive e principalmente, no caso em debate, pois a educação sexual dos jovens certamente não é igual, haja vista as diferenças sociais e culturais encontradas em um país de dimensões continentais. Com efeito, não se pode considerar crime fato que não tenha violado, verdadeiramente, o bem jurídico tutelado —a liberdade sexual—, haja vista constar dos autos que as menores já se prostituíam havia algum tempo.

A repercussão da decisão no meio social foi extremamente negativa, com críticas severas à relativização da presunção de violência, por parte de órgãos governamentais e organizações não governamentais ligados à defesa dos direitos humanos, os quais entenderam que o entendimento acabaria por incentivar a prostituição infantil.

Até mesmo o Escritório Regional para a América do Sul do Alto Comissariado das Nações Unidas para os Direitos Humanos (ACNUDH) criticou a decisão do Superior Tribunal de Justiça, por meio de Amerigo Incalcaterra, Representante Regional do ACNUDH para a América do Sul, o qual afirmou: "É impensável que a vida sexual de uma criança possa ser usada para revogar seus direitos".

Tamanho o impacto negativo da decisão que o Superior Tribunal de Justiça, em raríssima atitude, resolveu divulgar nota pública a respeito, com o seguinte teor: ${ }^{8}$

Esclarecimentos à sociedade

Em relação à decisão da Terceira Seção do Superior Tribunal de Justiça, objeto da notícia "Presunção de violência contra menor de 14 anos em estupro é relativa", esclarecemos que:

1. O STJ não institucionalizou a prostituição infantil.

Presunção de violencia contra menor é relativa, 27 de março de 2012 http://www.conjur.com.br/2012mar-27/presuncao-violencia-menor-vitima-estupro-relativa (Acesso: 20 fev. 2015).

8 http://www.stj.jus.br/portal_stj/publicacao/engine.wsp?tmp.area=398\&tmp.texto=105290 
A decisão não diz respeito à criminalização da prática de prostituição infantil, como prevista no Estatuto da Criança e do Adolescente ou no Código Penal após 2009 .

A decisão trata, de forma restrita e específica, da acusação de estupro ficto, em vista unicamente da ausência de violência real no ato.

A exploração sexual de crianças e adolescentes não foi discutida no caso submetido ao STJ, nem mesmo contra o réu na condição de "cliente". Também não se trata do tipo penal "estupro de vulnerável", que não existia à época dos fatos, assim como por cerca de 70 anos antes da mudança legislativa de 2009.

2. Não é verdade que o STJ negue que prostitutas possam ser estupradas.

A prática de estupro com violência real, contra vítima em qualquer condição, não foi discutida.

A decisão trata apenas da existência ou não, na lei, de violência imposta por ficção normativa, isto é, se a violência sempre deve ser presumida ou se há hipóteses em que menor de 14 anos possa praticar sexo sem que isso seja estupro.

3. A decisão do STJ não viola a Constituição Federal.

4. O STJ decidiu sobre a previsão infraconstitucional, do Código Penal, que teve vigência por cerca de 70 anos, e está sujeita à eventual revisão pelo STF. Até que o STF decida sobre a questão, presume-se que a decisão do STJ seja conforme o ordenamento constitucional. Entre os princípios constitucionais aplicados, estão o contraditório e a legalidade estrita.

Há precedentes do STF, sem força vinculante, mas que afirmam a relatividade da presunção de violência no estupro contra menores de 14 anos. Um dos precedentes data de 1996.

O próprio STJ tinha entendimentos anteriores contraditórios, e foi exatamente essa divisão da jurisprudência interna que levou a questão a ser decidida em embargos de divergência em recurso especial.

4. O STJ não incentiva a pedofilia. 
As práticas de pedofilia, previstas em outras normas, não foram discutidas. A única questão submetida ao STJ foi o estupro — conjunção carnal mediante violência ou grave ameaça— sem ocorrência de violência real.

A decisão também não alcança práticas posteriores à mudança do Código Penal em 2009, que criou o crime de "estupro de vulnerável" e revogou o artigo interpretado pelo STJ nessa decisão.

5. O STJ não promove a impunidade.

Se houver violência ou grave ameaça, o réu deve ser punido. Se há exploração sexual, o réu deve ser punido. O STJ apenas permitiu que o acusado possa produzir prova de que a conjunção ocorreu com consentimento da suposta vítima.

6. O presidente do STJ não admitiu rever a decisão.

O presidente do STJ admitiu que o tribunal pode rever seu entendimento, não exatamente a decisão do caso concreto, como se em razão da má repercussão.

A hipótese, não tendo a decisão transitada em julgado, é normal e prevista no sistema. O recurso de embargos de declaração, já interposto contra decisão, porém, não se presta, em regra, à mudança de interpretação.

Nada impede, porém, que o STJ, no futuro, volte a interpretar a norma, e decida de modo diverso. É exatamente em vista dessa possível revisão de entendimentos que o posicionamento anterior, pelo caráter absoluto da presunção de violência, foi revisto.

7. O STJ não atenta contra a cidadania.

O STJ, em vista dos princípios de transparência que são essenciais à prática da cidadania esclarecida, divulgou, por si mesmo, a decisão, cumprindo seu dever estatal.

Tomada em dezembro de 2011, a decisão do STJ foi divulgada no dia seguinte à sua publicação oficial. Nenhum órgão do Executivo, Legislativo ou Ministério 
Público tomou conhecimento ou levou o caso a público antes da veiculação pelo STJ, por seus canais oficiais e de comunicação social.

A polêmica e a contrariedade à decisão fazem parte do processo democrático. Compete a cada Poder e instituição cumprir seu papel e tomar as medidas que, dentro de suas capacidades e possibilidades constitucionais e legais, considere adequadas.

O Tribunal da Cidadania, porém, não aceita as críticas que avançam para além do debate esclarecido sobre questões públicas, atacam, de forma leviana, a instituição, seus membros ou sua atuação jurisdicional, e apelam para sentimentos que, ainda que eventualmente majoritários entre a opinião pública, contrariem princípios jurídicos legítimos.

Embora o julgamento tenha incidido sobre fato anterior à edição da Lei 12.015 de 2009, a reação social demonstra que há forte expectativa pela vedação absoluta de contato sexual com menores de 14 anos, orientação que deve acabar prevalecendo. Em virtude de se tratar de legislação do ano de 2009, não há ainda número expressivo de julgamentos em última instância, mas alguns julgados realizados sob a égide das novas normas demonstram que deverá prevalecer a concepção pela presunção absoluta de violência em tais hipóteses, senão vejamos:

AGRAVO REGIMENTAL NO RECURSO ESPECIAL. ESTUPRO DE VULNERÁVEL. PRÁTICA DE CONJUNÇÃO CARNAL OU DE ATO LIBIDINOSO DIVERSO CONTRA MENOR. PRESUNÇÃO DE VIOLÊNCIA. NATUREZA ABSOLUTA. ART. 217-A DO CP. AGRAVO REGIMENTAL IMPROVIDO. 1. Para a consumação do crime de estupro de vulnerável, não é necessária a conjunção carnal propriamente dita, mas qualquer prática de ato libidinoso contra menor. Jurisprudência do STJ. 2. Agravo regimental improvido. (AgRg no REsp 1244672/MG, Rel. Ministro CAMPOS MARQUES (DESEMBARGADOR CONVOCADO DO TJ/PR), QUINTA TURMA, julgado em 21/05/2013, DJe 27/05/2013).

Há que se atentar, todavia, para o fato de que o art. 217-A do Código Penal é dotado de graves defeitos de proporcionalidade. Primeiramente, porque a pena mínima se revela extremamente elevada, a ponto de obrigar o cumprimento inicial em regime fechado, por um prazo não inferior a três anos, já que se trata de crime hediondo. Vale ressaltar que a pena mínima para o homicídio simples no ordenamento brasi- 
leiro é de seis anos de reclusão, e não se considera como crime hediondo, de modo que é possível o início de cumprimento em regime diverso do fechado.

Por outro lado, o tipo penal abrange um espectro muito amplo de condutas e contempla qualquer ato libidinoso. Daí que um simples beijo lascivo em um menor de 14 anos poderá sujeitar o agente, em tese, a gravíssimas sanções, que talvez fossem menores se houvesse roubado, lesionado gravemente ou mesmo matado a mesma vítima.

Essas graves desproporcionalidades podem ser a causa dos impulsos doutrinários e jurisprudenciais pela relativização da presunção de violência, em nome de uma pena mais justa e adequada à gravidade da conduta, ou mesmo por pena nenhuma, em lugar de pena desproporcional. Cuida-se, todavia, de interpretação contra legem. Se ao longo dos anos tal interpretação se sustentou na necessidade de atualização da norma penal, que era datada do ano de 1940, atualmente já não se sustenta, pois, no ano de 2009, o legislador ratificou o entendimento pela vulnerabilidade absoluta do menor de 14 anos.

Corroborou-se, assim, a noção de que a norma impõe um dever geral de abstenção da conduta de manter conjunção carnal ou qualquer ato libidinoso com pessoa menor de 14 anos, na medida em que tais indivíduos não têm a capacidade de aquiescer com a prática de atos sexuais. As desproporcionalidades do dispositivo legal por certo que merecem correção, de forma a permitir maior maleabilidade ao julgador para resolução do caso concreto, quiçá afastando mesmo a pena de prisão em alguns casos.

O que não é possível, porém, é a relativização do alcance de norma de extrema relevância para a tutela da liberdade e do desenvolvimento saudável de indivíduos ainda sem formação intelectual completa. A relativização, não há como negar, incentiva a exploração sexual de crianças e adolescentes, pois permite que um adulto mantenha relações sexuais com uma criança apenas porque esta já está entregue à prostituição. Ora, o fato de uma criança já haver sido objeto de práticas sexuais inúmeras vezes, mesmo que com seu consentimento, não faz com que adquira a maturidade necessária para passar a consentir validamente com os atos sexuais. A sua condição de vulnerável impõe que adultos se abstenham de aproximações com finalidades sexuais. 


\section{Conclusão}

Em razão da recente alteração legislativa promovida pela Lei 12.015 de 2009, que acrescentou o art. 217-A ao Código Penal Brasileiro, está superada a discussão em torno do caráter absoluto ou relativo da presunção de violência no caso de relações sexuais consentidas com menores de 14 anos de idade.

Assim sucede porque, contrariamente às normas anteriores, a nova legislação sequer cogita da existência de violência para a caracterização da figura típica e define como estupro de vulnerável meramente a prática de ato libidinoso com menor de 14 anos de idade. Não bastasse a taxatividade da previsão normativa, a justificação do projeto que culminou na edição da Lei 12.015 de 2009 não permite dúvidas a respeito da intenção legislativa:

O art. 217-A, que tipifica o estupro de vulneráveis, substitui o atual regime de presunção de violência contra criança ou adolescente menor de 14 anos, previsto no art. 224 do Código Penal. Apesar de poder a CPMI advogar que é absoluta a presunção de violência de que trata o art. 224, não é esse o entendimento em muitos julgados. O projeto de reforma do Código Penal, então, destaca a vulnerabilidade de certas pessoas, não somente crianças e adolescentes com idade até 14 anos, mas também a pessoa que, por enfermidade ou deficiência mental, não possuir discernimento para a prática do ato sexual, e aquela que não pode, por qualquer motivo, oferecer resistência; e com essas pessoas considera como crime ter conjunção carnal ou praticar outro ato libidinoso; sem entrar no mérito da violência e sua presunção. Trata-se de objetividade fática.

Não há espaço, portanto, para a relativização da presunção de violência estupro de vulnerável, pois está clara a política criminal instituída pela legislação, no sentido de dispensar até mesmo a presunção de violência. Não se coaduna a legislação com consentimento de menores de 14 anos com atos sexuais, ainda que já iniciados sexualmente em alguma intensidade. Sua finalidade é a proteção a vulneráveis, por meio da punição àqueles que deles se aproximarem com intenções libidinosas.

O acertado rigor legislativo, contudo, não prescinde da necessidade de melhor adequação da resposta penal, pois andou mal o legislador ao estabelecer sanções deveras excessivas, sem permitir ao julgador maior regulação da pena conforme as circunstâncias do caso concreto. 
Não obstante, a legislação tem o mérito de encerrar as discussões em torno da relativização da presunção de violência, que muitas vezes levava a digressões processuais em torno do tamanho da experiência sexual da vítima, em completa inversão de valores, e com lamentável incentivo à exploração sexual de crianças e adolescentes.

\section{Referências}

Bitencourt, Cezar Roberto. Tratado de direito penal: parte especial. 5a ed. São Paulo: Saraiva, 2011. Cunha, Rogério Sanches. Direito Penal: Parte especial. $3 a$ ed. v. 3, revista, atualizada e ampliada. São Paulo: Revista dos Tribunais. 2010. Coleção Ciências Criminais. v. 3. Coord. Luiz Flávio Gomes e Rogério Sanches Cunha.

Cunha, Rogério Sanches, Luiz Flávio Gomes Gomes e Valerio de Oliveira Mazzuoli. Comentários à Reforma Criminal de 2009 e à Convenção de Viena sobre o Direito dos Tratados. São Paulo: RT, 2009.

Delmanto, Celso, Roberto Delmanto, Roberto Delmanto Junior e Fabio de Almeida Delmanto. Código penal comentado. 8a ed. São Paulo: Saraiva, 2010.

Gentil, Plínio. "O novo estupro e a Lei dos Crimes Hediondos: Problemas de sobra". Revista Magister de Direito Penal e Processual Penal, 37 (2012): 76- 82.

Giorgis, José Carlos Teixeira. "Crimes Sexuais e a Pessoa Vulnerável". Revista Magister de Direito Penal e Processual Penal, 6, núm. 34 (2010): 20-34.

Greco, Rogério. Curso de Direito Penal: parte geral. v. I. 10a ed. Rio de Janeiro: Impetus, 2008. Leal, João José e Rodrigo José Leal. "Estupro Comum e a Figura do Estupro de Pessoa Vulnerável: Novo Tipo Penal Unificado". Revista Magister de Direito Penal e Processual Penal, 6, núm. 32 (2009): 52-77.

Machado, Antonio Claudio da Costa, ed., David Teixeira de Azevedo, coord. Código Penal Interpretado: Artigo por artigo. Barueri, SP: Manole, 2011.

Mendonça, Andrey Borges de. Reforma do Código Penal de Processo Penal. Comentada — artigo por artigo. 2a ed. Revista, atualizada e ampliada. São Paulo: Método, 2009.

Navarrete, Sonia Ariza e Kohen, Beatriz. Trata de personas con fines de explotación sexual: cuestiones interjurisdicionales. Buenos Aires: Ad-Hoc, 2013.

Nucci, Guilherme de Souza. Crimes contra a dignidade sexual — Comentários à Lei 12.015 de 7 de agosto de 2009. São Paulo: RT, 2009.

Nucci, Guilherme de Souza. Manual de direito penal. 7a ed. São Paulo: Revista dos Tribunais, 2011. Prado, Luiz Regis. Curso de direito penal brasileiro. V. 2: parte especial, arts. 121 a 249. 9a ed. Revista, altualizada e amplicada. São Paulo: Editora Revistas dos Tribunais, 2010. Zaffaroni, Eugenio Raúl e Pierangeli, José Henrique. Manual de Direito Penal Brasileiro. v. 1. Parte Geral. 8a ed. Revista e atualizada. São Paulo: Ed. Revista dos Tribunais, 2010. 